Original article

\title{
The predictive capacity of DSM-5 symptom severity and impulsivity on response to cognitive-behavioral therapy for gambling disorder: A 2-year longitudinal study
}

\author{
Gemma Mestre-Bach $^{\mathrm{a}, \mathrm{b}, 1}$, Trevor Steward ${ }^{\mathrm{a}, \mathrm{b}, 1}$, Roser Granero ${ }^{\mathrm{b}, \mathrm{d}}$, \\ Fernando Fernández-Aranda ${ }^{\mathrm{a}, \mathrm{b}, \mathrm{c}}$, Amparo del Pino-Gutiérrez ${ }^{\mathrm{a}, \mathrm{e}}$, \\ Núria Mallorquí-Baguéa,b ${ }^{a,}$ Teresa Mena-Moreno ${ }^{\mathrm{a}, \mathrm{b}}$, Cristina Vintró-Alcaraz ${ }^{\mathrm{a}, \mathrm{b}}$, \\ Laura Moragas $^{\mathrm{a}}$, Neus Aymamía,f ${ }^{\text {, }}$ Mónica Gómez-Peña ${ }^{a}$, Jéssica Sánchez-González ${ }^{\mathrm{a}}$, \\ Zaida Agüera ${ }^{\mathrm{a}, \mathrm{b}}$, María Lozano-Madridd ${ }^{\mathrm{a}, \mathrm{b}}$, José M. Menchón ${ }^{\mathrm{a}, \mathrm{c}, \mathrm{g}}$, \\ Susana Jiménez-Murcia ${ }^{\mathrm{a}, \mathrm{b}, \mathrm{c}, *}$ \\ a Department of Psychiatry, Bellvitge University Hospital-IDIBELL, C/Feixa Llarga s/n, Hospitalet de Llobregat, 08907 Barcelona, Spain \\ b Ciber Fisiopatología Obesidad y Nutrición (CIBERObn), Instituto de Salud Carlos III, C/Monforte de Lemos, 3-5, Pabellón 11, Planta 0, 28029 Madrid, Spain \\ ${ }^{\mathrm{c}}$ Department of Clinical Sciences, School of Medicine, University of Barcelona, C/Feixa Llarga s/n, Hospitalet de Llobregat, 08907 Barcelona, Spain \\ d Departament de Psicobiologia i Metodologia de les Ciències de la Salut, Universitat Autònoma de Barcelona, C/Fortuna Edificio B, Bellaterra, Cerdanyola del \\ Vallès, 08193 Barcelona, Spain

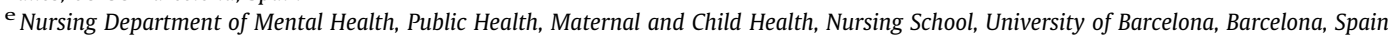 \\ ${ }^{\mathbf{f}}$ Departament de Psicologia Clínica i Psicobiologia, Facultat de Psicologia, Universitat de Barcelona, Passeig de la Vall d'Hebron, 171, 08035 Barcelona, Spain \\ g CIBER Salud Mental (CIBERSAM), Instituto de Salud Carlos III, C/Monforte de Lemos 3-5, Pabellón 11, Planta 0, 28029 Madrid, Spain
}

\section{A R T I C L E I N F O}

\section{Article history:}

Received 28 June 2018

Received in revised form 6 September 2018

Accepted 7 September 2018

Available online 31 October 2018

\section{Keywords:}

Gambling disorder

Cognitive-behavioral therapy

Impulsivity

DSM-5

Dropout

Relapse

\begin{abstract}
A B S T R A C T
Background: DSM-5 proposed a new operational system by using the number of fulfilled criteria as an indicator of gambling disorder severity. This method has proven to be controversial among researchers and clinicians alike, due to the lack of studies indicating whether severity, as measured by these criteria, is clinically relevant in terms of treatment outcome. Additionally, numerous studies have highlighted the associations between gambling disorder and impulsivity, though few have examined the impact of impulsivity on long-term treatment outcomes.

Methods: In this study, we aimed to assess the predictive value of DSM-5 severity levels on response to cognitive-behavioral therapy (CBT) in a sample of male adults seeking treatment for gambling disorder $(n=398)$. Furthermore, we explored longitudinal predictors of CBT treatment response at a follow-up, considering UPPS-P impulsivity traits.

Results: Our study failed to identify differences in treatment outcomes between patients categorized by DSM-5 severity levels. Higher baseline scores in negative urgency predicted relapse during CBT treatment, and higher levels of sensation seeking were predictive of drop-out from short-term treatment, as well as of drop-out at 24-months.

Conclusions: These noteworthy findings raise questions regarding the clinical utility of DSM-5 severity categories and lend support to the implementation of dimensional approaches for gambling disorder.
\end{abstract}

(c) 2018 Elsevier Masson SAS. All rights reserved.

\footnotetext{
* Corresponding author at: Department of Psychiatry, Bellvitge University Hospital-IDIBELL and CIBERObn, c/ Feixa Llarga s/n, 08907, Hospitalet de Llobregat, Barcelona, Spain.

E-mail address: sjimenez@bellvitgehospital.cat (S. Jiménez-Murcia).

1 Shared first authorship.
}

\section{Introduction}

Gambling disorder (GD) constitutes a psychiatric condition categorized in the latest version of the Diagnostic and Statistical Manual of Mental Health Disorders (DSM-5) [1] as a nonsubstance-related addiction. This disorder is characterized by a recurrent and persistent pattern of gambling behavior that leads to clinically significant distress. Patients with GD often suffer from 
cognitive distortions, such as illusions of control [2,3], high psychopathology levels [4-6], and dysfunctional personality traits (such as high novelty seeking) [7-9].

In addition to this clinical symptomatology, numerous studies have highlighted the associations between GD and impulsivity [10-13]. Specifically, there is evidence to support that trait impulsivity affects both the aetiology and maintenance of this behavioral addiction $[14,15]$. The most used framework in recent years for the study of GD has been the UPPS-P [16,17]. It categorizes impulsivity into five independent dimensions: sensation seeking, which refers to one's disposition to seek exciting experiences; (lack of) perseverance, that reflects the tendency to not persist in an activity that can be arduous; (lack of) premeditation shows the tendency to act without considering the consequences of the behavior; and positive and negative urgency, understood as emotionally charged impulsive behaviors in response to positive or negative moods $[18,19]$.

In the case of GD, the scales that best distinguish treatmentseeking patients from healthy controls are lack of perseverance and positive and negative urgency, with GD patients endorsing greater levels in all three measures $[15,20]$. It is common for patients with GD to report using gambling behavior to mitigate states of anxiety or depression, possibly due to impaired emotion regulation mechanisms [20-22]. The role of sensation seeking, as assessed by the UPPS-P, is not clear in the case of GD and some studies do not support higher levels of this trait in comparison with healthy controls $[20,23,24]$. Finally, lack of premeditation has been shown to be associated with poor decision-making abilities, which is a common feature in patients with GD $[16,17,25]$.

According to the DSM-5, the greater presence of GD symptomatology increases the severity of the disorder [1]. In this vein, existing research recognizes the bond between impulsivity and GD severity [26-28]. In view of this association and in order to carry out classification from a dimensional point of view, the DSM-5 proposed a new operationalization of clinical severity by numbering criteria. This system is used as an indicator of GD severity and is divided into three levels: mild (four to five criteria), moderate (six to seven), and severe (eight or nine) [1,29]. However, this new classification has proven to be controversial among researchers and clinicians alike, highlighting the need to assess whether severity, as measured by these criteria, is clinically relevant [29-31].

A wide range of treatment options are available for GD, including various psychological approaches (e.g. self-help groups and peer-support interventions) and pharmacological treatment [32]. However, not all patients with GD obtain long-term benefits from psychological interventions, with success rates at a 6-month 1-year follow-up ranging anywhere from $30 \%$ and to $71 \%$ [33-36]. A recent systematic review of evidence relating to pre-treatment predictors of gambling outcomes following psychological treatment identified older age, lower gambling symptom severity, lower levels of gambling behaviors and alcohol use, and higher treatment session attendance as likely predictors of successful treatment outcome [37]. Additionally, higher levels of sensation seeking (though not as measured by the UPPS-P) were associated with negative treatment outcomes at post-treatment or mediumterm follow-up [37]. Findings such as these are practical for clinicians in choosing treatment strategies by allowing them to take into account the characteristics of the individual seeking treatment. Nonetheless, evidence regarding the clinical utility of current working definition of GD symptom severity boundaries is scare $[29,31]$ and recent calls have been made to incorporate broader outcome domains that extend beyond disorder-specific symptoms in order to develop a single comprehensive to measure all aspects of gambling recovery [38].
Therefore, taking into account the findings described above, the aims of this study were threefold: 1 ) to explore the association between gambling-related variables and impulsivity traits in a sample of adult men who met criteria for GD; b) to estimate the predictive capacity of the impulsivity measures on GD treatment outcome (after 4 months of CBT treatment and at a two-year follow-up), namely considering relapse and dropout as outcome measures; and c) to examine the associations between DSM-5 severity categories on treatment outcome.

\section{Material and methods}

\subsection{Participants and procedure}

An initial sample of 519 patients diagnosed with GD from the Department of Psychiatry at a University Hospital, recruited between March 2013 and July 2017, was considered. They were voluntarily derived to the Gambling Disorder Unit through general practitioners or via other healthcare professionals. From this sample, 112 cases were excluded due to the fact that they decided not to enter treatment. Moreover, female patients $(n=8)$ and one case an incomplete evaluation were excluded. A total of 398 male patients were included in the final sample. Exclusion criteria for the study were the presence of a mental disorder (i.e. schizophrenia or other psychotic disorders) or intellectual disability. Patients were screened via a structured interview by experienced clinical psychologists and psychiatrists before being included in the study sample. These same therapists carried out the CBT therapy intervention.

The present study was carried out in accordance with the latest version of the Declaration of Helsinki. The University Hospital Clinical Research Ethics Committee approved the study, and written informed consent was obtained from all participants.

\subsection{Treatment}

The cognitive-behavioral therapy (CBT) group treatment program used in this study consisted of 16 weekly outpatient sessions at a University Hospital, lasting $90 \mathrm{~min}$ each. The follow-up period of visits included evaluations at 1, 3, 6, 12 and 24 months. CBT groups were led by an experienced clinical psychologist as well as a licensed co-therapist. To ensure treatment fidelity, treatment providers were trained on how to adhere closely to the treatment manual [39]. The goal of this treatment plan was to educate patients on how to implement CBT strategies in order to minimize all types of gambling behavior in order to eventually obtain full abstinence. The topics addressed in the treatment plan included: psychoeducation regarding the disorder (its course, vulnerability factors, diagnostic criteria, etc.), stimulus control (money management, avoidance of potential triggers, self-exclusion programs, etc.), response prevention (alternative and compensatory behaviors), cognitive restructuring focused on illusions of control over gambling and magical thinking, emotion-regulation skills training, and other relapse prevention techniques. This treatment program has already been described elsewhere [39] and its short and medium-term effectiveness has been reported in other studies $[36,40,41]$. Throughout treatment, attendance to treatment sessions, control of spending and the occurrence of relapses were recorded weekly on an observation sheet. A relapse was defined as the occurrence of a gambling episode once treatment had begun. This is common for many studies carried out with patients who meet criteria for GD [41-43]. Failure to attend three consecutive CBT sessions was considered a criterion for dropout. 


\subsection{Instruments}

\subsubsection{DSM-5 Criteria [1]}

Patients were diagnosed with pathological gambling if they met DSM-IV-TR criteria for this disorder [44]. It should be noted that with the release of the DSM-5 [1], the term pathological gambling was replaced with GD. All patient diagnoses were reassessed and recodified post hoc and only patients who met DSM-5 criteria for GD were included in our analysis.

\subsubsection{South oaks gambling screen (SOGS) [45]}

This 20-item screening questionnaire discriminates between probable pathological, problem and non-problem gamblers based on the frequency and nature of gambling behaviors. The Spanish validation used in this work showed excellent internal consistency $(\alpha=0.94)$ and test-retest reliability $(r=0.98)$ [46].

\subsubsection{Impulsive behavior scale (UPPS-P) [47]}

The UPPS-P measures five facets of impulsivity through self-report on 59 items: negative urgency; positive urgency; lack of premeditation; lack of perseverance; and sensation seeking. Individuals are asked to consider acts/incidents during the last 6 months when rating their behaviors and attitudes. The Spanis H-L anguage adaptation showed good reliability (Cronbach's $\alpha$ between 0.79 and 0.93 ) and external validity [19]. Consistency in the study sample was between good ( $\alpha=0.75$ for lack of perseverance scale) to excellent ( $\alpha=0.92$ for positive urgency).

\subsubsection{Other sociodemographic and clinical variables}

Additional sociodemographic and variables related to gambling were measured using a semi-structured, face-to-face clinical interview described elsewhere [39].

\subsection{Statistics}

Statistical analyses were carried out with Stata 15 for Windows. Firstly, the predictive capacity of GD severity (according to DSM-5 criteria) and UPPS-P impulsivity levels on relapse during CBT treatment, dropout during CBT and dropout in completing patients at the 24-month follow-up was assessed with binary logistic regression adjusted for the patients' age. These models were adjusted into two blocks: a) first block entered and fixed the covariate age; b) second block added the predictive independent variables through the ENTER method. The Hosmer-Lemeshow test assessed goodness-of-fit ( $p>.05$ was considered adequate fit), global predictive capacity for the predictive variables entered into the second block was assessed through the changes in Nagelkerke's pseudo- $R^{2}$ coefficient $\left(\Delta R^{2}\right)$, and the global discriminative capacity of the final model was estimated via the area under the ROC curve (AUC).

Comparison between UPPS-P scores at baseline between the categorical GD severity groups (using DSM-5 criteria) was based on analysis of variance (ANOVA), adjusted for the participants' age, including pairwise comparisons to assess differences between the groups.

Finally, survival analyses measured the time to dropout and the first relapse during the CBT intervention, as well as the comparison of the GD severity groups at baseline. This study obtained the Kaplan-Meier (product-limit) estimator and used the Cox's regression adjusted for the participants' age to compare the survival cumulate curves between the three GD severity groups (i.e. mild, moderate, and severe). The survival function is a method used to measure the probability of patients "living" (surviving without the presence of the outcome, in this study without dropout and without the presence of gambling relapses) for a certain amount of time after the intervention. One of the most relevant advantages of this procedure is that it allows for the modeling of censored data, which occurs if patients withdraws from the study $[48,49]$.

\section{Results}

\subsection{Description of the sample}

The mean age of the study sample was 41.5 years ( $S D=13.1)$, the mean age of GD onset was 28.5 years ( $S D=10.8)$, with a mean duration of 6.5 years $(\mathrm{SD}=6.4)$. Table 1 includes a complete sociodemographic and clinical description of study sample.

\subsection{Predictive capacity of GD severity and impulsivity levels treatment outcome}

The number of participants who dropout during the CBT program was $n=182$ (risk of dropout equal to $45.7 \%$; $95 \%$ confidence interval, $95 \% \mathrm{CI}$ : $40.8 \%$ to $50.6 \%$ ) and the participants who reported gambling episodes during the course of the treatment was $n=119$ (risk of relapses: $29.9 \%$; $95 \% \mathrm{CI}$ : $25.4 \%$ to $34.4 \%$ ). The attrition from treatment completion to the 24-month follow-up was high (risk of dropout during the 2 years follow-up equal to $89.8 \%$ : $95 \% \mathrm{CI}$ : $85.8 \%$ to $93.8 \%$ ). Table 2 includes the binary logistic regression models assessing the predictive capacity of baseline GD severity (the number of DSM-5 criteria) and UPPS-P impulsivity levels on treatment outcome (all the models are adjusted for the covariate age). All models in this table obtained good fitting indexes ( $p>.05$ in the H-L test).

Table 1

Sample description $(\mathrm{n}=398)$.

\begin{tabular}{|c|c|c|c|c|c|c|}
\hline Sociodemographic variables & $n$ & $\%$ & Clinical variables & $\alpha$ & Mean & SD \\
\hline OriginSpain & 375 & $94.2 \%$ & Age (years-old) & & 41.52 & 13.12 \\
\hline Other country & 23 & $5.8 \%$ & Gambling disorder onset (years) & & 28.48 & 10.76 \\
\hline Civil statusSingle & 196 & $49.2 \%$ & Duration of gambling (years) & & 6.53 & 6.44 \\
\hline Married-partner & 156 & $39.2 \%$ & Mean bets per episode (euros) & & 149.9 & 491.2 \\
\hline Separated-divorced & 46 & $11.6 \%$ & Largest bet in an episode (euros) & & 1607.1 & 5301.8 \\
\hline Education levelPrimary & 227 & $57.0 \%$ & Cumulate debts, at present (euros) & & $22,048.8$ & 164228.9 \\
\hline Secondary & 142 & $35.7 \%$ & DSM-5 total criteria & .744 & 7.27 & 1.52 \\
\hline University & 29 & $7.3 \%$ & SOGS total criteria & .740 & 11.26 & 2.74 \\
\hline EmploymentUnemployed & 173 & $43.5 \%$ & UPPS-P Lack of premeditation & .846 & 24.40 & 6.57 \\
\hline \multirow[t]{4}{*}{ Employed } & 225 & $56.5 \%$ & UPPS-P Lack of perseverance & .778 & 22.13 & 5.64 \\
\hline & & & UPPS-P Sensation seeking & .860 & 27.63 & 8.89 \\
\hline & & & UPPS-P Positive urgency & .918 & 32.18 & 10.55 \\
\hline & & & UPPS-P Negative urgency & .806 & 33.14 & 7.10 \\
\hline
\end{tabular}

Note. SD: standard deviation. Cronbach's alpha in the sample. SOGS: South Oaks Gambling Screen. 
Table 2

Predictive capacity of DSM-5 GD severity and the UPPS-P scores on treatment outcome (second block of the regressions adjusted for age).

\begin{tabular}{|c|c|c|c|c|c|c|c|c|c|c|}
\hline & $B$ & $S E$ & Wald & $p$ & OR & $95 \% \mathrm{CI}(\mathrm{OR})$ & & $\Delta \mathrm{R}^{2}$ & $\mathrm{H}-\mathrm{L}$ & AUC \\
\hline \multicolumn{11}{|l|}{ Drop out during CBT } \\
\hline Age (years-old) & -0.017 & 0.009 & 3.728 & .054 & 0.98 & 0.97 & 1.00 & .047 & .083 & .658 \\
\hline Severity of GD (DSM-5 total) & -0.062 & 0.079 & 0.606 & .436 & 0.94 & 0.81 & 1.10 & & & \\
\hline UPPS-P Lack of premeditation & -0.001 & 0.021 & 0.003 & .956 & 1.00 & 0.96 & 1.04 & & & \\
\hline UPPS-P Lack of perseverance & 0.051 & 0.024 & 4.745 & $.029 *$ & 1.05 & 1.01 & 1.10 & & & \\
\hline UPPS-P Sensation seeking & 0.049 & 0.013 & 13.517 & $<.001 *$ & 1.05 & 1.02 & 1.08 & & & \\
\hline UPPS-P Positive urgency & -0.002 & 0.015 & 0.012 & .914 & 1.00 & 0.97 & 1.03 & & & \\
\hline UPPS-P Negative urgency & 0.002 & 0.022 & 0.007 & .936 & 1.00 & 0.96 & 1.05 & & & \\
\hline \multicolumn{11}{|l|}{ Relapses during CBT } \\
\hline Age (years-old) & -0.008 & 0.009 & 0.815 & .367 & 0.99 & 0.97 & 1.01 & .026 & .516 & .602 \\
\hline Severity of GD (DSM-5 total) & -0.025 & 0.085 & 0.083 & .773 & 0.98 & 0.83 & 1.15 & & & \\
\hline UPPS-P Lack of premeditation & -0.012 & 0.021 & 0.319 & .572 & 0.99 & 0.95 & 1.03 & & & \\
\hline UPPS-P Lack of perseverance & 0.036 & 0.025 & 2.097 & .148 & 1.04 & 0.99 & 1.09 & & & \\
\hline UPPS-P Sensation seeking & 0.014 & 0.014 & 0.983 & .322 & 1.01 & 0.99 & 1.04 & & & \\
\hline UPPS-P Positive urgency & -0.012 & 0.015 & 0.569 & .451 & 0.99 & 0.96 & 1.02 & & & \\
\hline UPPS-P Negative urgency & 0.052 & 0.024 & 4.825 & $.028 *$ & 1.05 & 1.01 & 1.10 & & & \\
\hline \multicolumn{11}{|l|}{${ }^{1}$ Drop-out at 24 -month follow-up } \\
\hline Age (years-old) & -0.026 & 0.019 & 1.856 & .173 & 0.965 & 0.940 & 1.011 & .062 & .331 & .682 \\
\hline Severity of GD (DSM-5 total) & -0.040 & 0.184 & 0.047 & .828 & 0.961 & 0.671 & 1.377 & & & \\
\hline UPPS-P Lack of premeditation & -0.058 & 0.051 & 1.305 & .253 & 0.944 & 0.854 & 1.042 & & & \\
\hline UPPS-P Lack of perseverance & 0.081 & 0.055 & 2.183 & .140 & 1.085 & 0.974 & 1.208 & & & \\
\hline UPPS-P Sensation seeking & 0.070 & 0.035 & 3.938 & $.047^{*}$ & 1.072 & 1.001 & 1.149 & & & \\
\hline UPPS-P Positive urgency & -0.014 & 0.033 & 0.182 & .670 & 0.986 & 0.924 & 1.052 & & & \\
\hline UPPS-P Negative urgency & -0.048 & 0.053 & 0.827 & .363 & 0.953 & 0.859 & 1.057 & & & \\
\hline
\end{tabular}

Note. ${ }^{1}$ Model for patients who finished CBT treatment $(n=216)$.

$\Delta \mathrm{R}^{2}$ : increase in the Nagelkerke's pseudo $\mathrm{R}^{2}$ comparing blocks 1 and 2. H-L: Hosmer and Lemeshow test ( $p$-value). AUC: area under the ROC.

Bold: significant parameter (.05 level). Italics: coefficients for the covariate age. (Sample size: $n=398$ ).

The risk of drop out during the CBT program (the first model in Table 1) was higher for participants who reported higher lack of perseverance and sensation seeking scores. The risk of having a gambling episode (relapsing) during CBT treatment was higher for participants with higher negative urgency levels (the second model in Table 2). Finally, the risk of drop out during the two-year follow-up after the CBT program (the third model in Table 2, obtained for the subsample of patients who finished CBT treatment therapy without dropout) was increased for patients who reported higher scores in sensation seeking.

\subsection{Comparison of UPPS-P impulsivity levels between DSM-5 GD severity groups}

Table 3 includes the ANOVA comparison, adjusted for age, comparing baseline UPPS-P impulsivity levels between the three GD severity groups (mild, moderate, and severe) (Table S1, Supplementary material, includes comparisons for additional clinical measures of these groups). As a whole, mean positive and negative urgency levels increased with GD severity.

\subsection{Survival analysis comparing DSM-5 GD severity groups}

Fig. 1 contains the survival function estimated with the KaplanMeier method for the rate of dropout and relapses during the CBT program, stratified by DSM-5 gambling severity group (mild, moderate and severe). No statistical differences for these outcomes were found comparing the three groups: Cox's regression adjusted for the participants' age obtained $\chi^{2}$-wald $=0.02, d f=1, p=.892$ for dropout and $\chi^{2}$-wald $=0.02, d f=1, p=.892$ for relapses.

\section{Discussion}

The present study estimated, in a sample of male patients seeking treatment for GD, the predictive capacity of impulsivity traits and gambling severity on treatment outcome, namely considering relapse and dropout. We also sought to examine the associations between impulsivity, GD severity and treatment response.

Regarding the predictive model, sensation seeking was a predictor of dropout, both during treatment and in follow-up

Table 3

Comparison of UPPS-P scores based on DSM-5 GD severity categories: ANOVA adjusted for patients' age.

\begin{tabular}{|c|c|c|c|c|c|c|c|c|c|c|c|c|}
\hline \multirow[t]{3}{*}{ GD severity $\rightarrow$} & \multirow{2}{*}{\multicolumn{2}{|c|}{$\begin{array}{l}\text { Mild } \\
(4-5 \text { criteria }) \\
(n=65)\end{array}$}} & \multirow{2}{*}{\multicolumn{2}{|c|}{$\begin{array}{l}\text { Moderate } \\
(6-7 \text { criteria }) \\
(n=133)\end{array}$}} & \multirow{2}{*}{\multicolumn{2}{|c|}{$\begin{array}{l}\text { Severe } \\
(8-9 \text { criteria }) \\
(n=200)\end{array}$}} & \multicolumn{6}{|c|}{ Pairwise comparisons } \\
\hline & & & & & & & \multicolumn{2}{|c|}{$\begin{array}{l}\text { Mild } \\
\text { vs moderate }\end{array}$} & \multicolumn{2}{|c|}{$\begin{array}{l}\text { Mild } \\
\text { vs severe }\end{array}$} & \multicolumn{2}{|c|}{$\begin{array}{l}\text { Moderate } \\
\text { vs severe }\end{array}$} \\
\hline & Mean & $S D$ & Mean & $S D$ & Mean & $S D$ & $p$ & $|d|$ & $p$ & $|d|$ & $p$ & $|d|$ \\
\hline Lack of premeditation & 22.60 & 6.81 & 23.76 & 6.45 & 25.42 & 6.34 & .228 & 0.18 & $.002^{*}$ & 0.43 & $.023^{*}$ & 0.26 \\
\hline Lack of perseverance & 20.86 & 6.24 & 21.59 & 5.70 & 22.91 & 5.30 & .389 & 0.12 & $.012^{*}$ & 0.35 & $.038^{*}$ & 0.24 \\
\hline Sensation seeking & 26.26 & 9.00 & 26.44 & 8.37 & 28.87 & 8.89 & .886 & 0.02 & $.032^{*}$ & 0.29 & $.011^{*}$ & 0.28 \\
\hline Positive urgency & 25.19 & 8.68 & 30.17 & 10.19 & 35.78 & 9.99 & $.001^{*}$ & $0.53^{\dagger}$ & $<.001^{*}$ & $1.13^{\dagger}$ & $<.001^{*}$ & 0.56 \\
\hline Negative urgency & 27.70 & 6.81 & 31.86 & 6.29 & 35.76 & 6.51 & $<.001^{*}$ & $\mathbf{0 . 6 3}$ & $<.001^{*}$ & $1.21^{\dagger}$ & $<.001^{*}$ & 0.61 \\
\hline
\end{tabular}

Note. SD: standard deviation. *Bold: significant comparison (.05 level).

${ }^{\dagger}$ Bold: effect size into the moderate $(|d|>0.50)$ to high range $(|d|>0.80)$. 

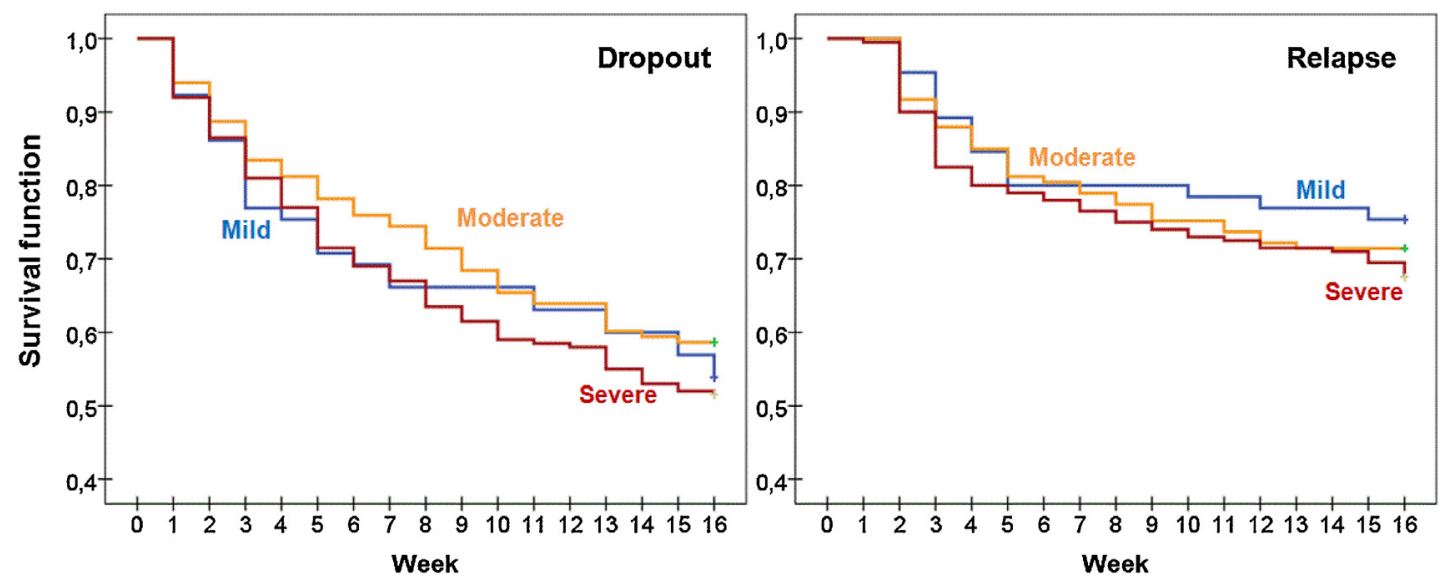

Fig. 1. Cumulative survival functions for dropout and relapse during the 16-week CBT program.

stages. To date, there is a paucity of scientific literature analyzing the association of this construct with GD treatment outcome. However, previous studies in the field suggest that patients with high levels of sensation present a clinical phenotype that could interfere with adherence to treatment guidelines [37,50,51]. These patients may be especially motivated at the start of treatment to become involved in a treatment program with the expectation of receiving the benefits of abstinence, but this interest in the novelty of treatment often quickly fades due to their personality profile [52]. Relatedly, lack of perseverance was another predictor of dropout during treatment and in the follow-up period. Other addiction studies have provided similar evidence, finding that treatment completers had significantly higher persistence levels than those who abandon therapy [53].

Finally, negative urgency was identified as a predictor of relapse during treatment in the present study. This finding broadly supports the results of other studies in addictions linking high levels of impulsivity with short-term and mid-term relapses [54]. More specifically, negative urgency has been associated with poorer therapy outcomes [55] and greater relapse risk. This leads us to postulate that patients with GD are more vulnerable to making rash decisions when experiencing negative mood states, such as frustration or anxiety, leading to more frequent relapses. Gambling behavior, in these cases, is therefore likely used as a means of negative reinforcement in order to regulate affective states. Moreover, it is known that in GD, as the disorder progresses, behavior is increasingly maintained by a pattern of negative reinforcement than positive reinforcement [56]. Therefore, impulsiveness could arise from seeking out relief from negative emotional states rather than from a need to obtain immediate reward [57]. From a phenomenological perspective, it is feasible that disinhibition plays a mediating role between these two dimensions [58,59], with numerous studies suggesting that inhibition is impaired in some patients with GD and that disinhibition, in turn, can be a risk factor for relapse $[60,61]$.

Another finding to emerge from the present study is the difference in urgency levels bearing in mind DSM-5 severity categories (mild, moderate and severe). Specifically, the present data uphold the position that in those cases in which the severity of GD is greater, levels of urgency are also higher. This observation dovetails with other research that found that impulsivity was a predictor of GD severity and poor prognosis [62,63].

Although other studies have associated greater GD severity with poorer response to treatment [37], our study failed to indentify differences in treatment response using DSM-5 GD severity categorizations. The DSM-5 provides nine diagnostic criteria for GD and it is pre-assumed that all criteria have an equal diagnostic impact [31]. One of the drawbacks of this dichotomous approach is that factors, such as the frequency and the level of distress brought about by gambling behaviors [29,59]. Our findings raise further questions regarding the clinical validity of merely summing the number of criteria endorsed by an individual and whether DSM-5 GD severity categories accurately reflect actual GD symptom severity, if each is weighted equally. In the line of the study by Bottesi et al. [58], future studies should consider contrasting dimensional measures with DSM-5 categories in order to determine which best serves as a predictor of treatment response. Doing so could aid clinicians in shifting away from categorical definitions of gambling and allow for more tailored treatment programs that bear in mind the patients' individual features that place them at greatest risk.

\subsection{Limitations}

The present study is not without its limitations. First, all data were collected from men who sought treatment and future studies would benefit from including women with GD. Second, impulsivity traits were assessed using self-report measures that are, in all likelihood, unable to fully capture the multi-factorial nature of impulsivity in GD patients. Third, our study only examined the effectiveness of one type of intervention and it would be useful to know if similar results are present using a multiple-arm study design [64]. Finally, it would have been of interest to take pharmacotherapy into account, being that GD patients frequently show comorbidities with other disorders (e.g. depression, attention deficit hyperactivity disorder) and that the use of medications could potentially have influenced impulsivity levels.

\section{Conclusions}

This study aimed to identify short- and long-term predictors of response to treatment in sample of treatment-seeking patients with GD. In concordance with other studies, our findings indicate that increased sensation-seeking levels were a predictor of abandoning treatment, along with greater lack of perseverance scores. Furthermore, we found that greater negative urgency scores increased the risk of relapsing during the 16-week CBT treatment program. However, contrary to our initial hypothesis, increased severity, as categorized by the DSM-5, was not indicative of poorer response to treatment. These results raise doubts with 
respect to the clinical utility of such severity categories and support the use of dimensional approaches in future studies.

\section{Declarations of interest}

None.

\section{Acknowledgements}

Financial support was received through the Ministerio de Economía y Competitividad (grant PSI2011-28349 and PSI201568701-R). FIS PI14/00290,FIS PI17/01167, and 18MSP001 - $2017 I 067$ received aid from the Ministerio de Sanidad, Servicios Sociales e Igualdad. CIBER Fisiología Obesidad y Nutrición (CIBERobn) and CIBER Salud Mental (CIBERSAM), both of which are initiatives of ISCIII. GMB is supported by a predoctoral AGAUR grant (2018 FI_B2 00174), co-financed by the European Social Fund, with the support of the Secretaria d'Universitats i Recerca del Departament d'Economia i Coneixement de la Generalitat de Catalunya. MLM, TMM and CVA are each supported by a predoctoral the Ministerio de Educación, Cultura y Deporte (FPU15/0291; FPU16/02087; FPU16/01453).

\section{Appendix A. Supplementary data}

Supplementary material related to this article can be found, in the online version, at doi:https://doi.org/10.1016/j.eurpsy.2018.09.002.

\section{References}

[1] American Psychiatric Association. Diagnostic and statistical manual of mental disorders. 5th ed. Washington, DC: American Psychiatric Association; 2013.

[2] Gaissmaier W, Wilke A, Scheibehenne B, McCanney P, Barrett HC. Betting on illusory patterns: probability matching in habitual gamblers. J Gambl Stud 2016;32(1):143-56.

[3] Del Prete F, Steward T, Navas JF, Fernández-Aranda F, Jiménez-Murcia S, Oei TPS, et al. The role of affect-driven impulsivity in gambling cognitions: convenience-sample study with a Spanish version of the Gambling-Related Cognitions Scale. J Behav Addict 2017;6(1):51-63.

[4] Sanacora RL, Whiting SW, Pilver CE, Hoff RA, Potenza MN. Relationships between problem-gambling severity and psychopathology as moderated by income. J Behav Addict 2016;5(3):429-38.

[5] Maremmani AGI, Gazzarrini D, Fiorin A, Cingano V, Bellio G, Perugi G, et al. Psychopathology of addiction: can the SCL90-based five-dimensional structure differentiate Heroin Use Disorder from a non-substance-related addictive disorder such as Gambling Disorder? Ann Gen Psychiatry 2018;17 (1):3.

[6] Barrault S, Bonnaire C, Herrmann F. Anxiety, depression and emotion regulation among regular online poker players. J Gambl Stud 2017;33 (4):1039-50.

[7] del Pino-Gutiérrez A, Jiménez-Murcia S, Fernández-Aranda F, Agüera Z, Granero R, Hakansson A, et al. The relevance of personality traits in impulsivity-related disorders: from substance use disorders and gambling disorder to bulimia nervosa. J Behav Addict 2017;6(3):396-405.

[8] Cerasa A, Lofaro D, Cavedini P, Martino I, Bruni A, Sarica A, et al. Personality biomarkers of pathological gambling: a machine learning study. J Neurosci Methods 2018;294:7-14.

[9] Mallorquí-Bagué N, Fernández-Aranda F, Lozano-Madrid M, Granero R, Mestre-Bach G, Baño M, et al. Internet gaming disorder and online gambling disorder: clinical and personality correlates. J Behav Addict 2017;6 (4):669-77.

[10] Mestre-Bach G, Steward T, Granero R, Fernández-Aranda F, Talón-Navarro MT, Cuquerella À, et al. Gambling and impulsivity traits: a recipe for criminal behavior? Front Psychiatry 2018;9:6.

[11] Savvidou LG, Fagundo AB, Fernández-Aranda F, Granero R, Claes L, MallorquíBaqué $\mathrm{N}$, et al. Is gambling disorder associated with impulsivity traits measured by the UPPS-P and is this association moderated by sex and age? Compr Psychiatry 2017;72:106-13.

[12] Chowdhury NS, Livesey EJ, Blaszczynski A, Harris JA. Pathological gambling and motor impulsivity: a systematic review with meta-analysis. J Gambl Stud 2017;33(4):1213-39.

[13] Steward T, Mestre-Bach G, Fernández-Aranda F, Granero R, Perales JC, Navas JF, et al. Delay discounting and impulsivity traits in young and older gambling disorder patients. Addict Behav 2017;71:96-103.

[14] Nower L, Derevensky JL, Gupta R. The relationship of impulsivity, sensation seeking, coping, and substance use in youth gamblers. Psychol Addict Behav 2004;18(1):49-55.
[15] Lutri V, Soldini E, Ronzitti S, Smith N, Clerici M, Blaszczynski A, et al. Impulsivity and gambling type among treatment-seeking disordered gamblers: an explorative study. J Gambl Stud 2018;1-14.

[16] Torres A, Catena A, Megías A, Maldonado A, Cándido A, Verdejo-García A, et al Emotional and non-emotional pathways to impulsive behavior and addiction. Front Hum Neurosci 2013;7:.

[17] Canale N, Vieno A, Bowden-Jones H, Billieux J. The benefits of using the UPPS model of impulsivity rather than the Big Five when assessing the relationship between personality and problem gambling. Addiction 2017;112(2):372-3.

[18] Berg JM, Latzman RD, Bliwise NG, Lilienfeld SO. Parsing the heterogeneity of impulsivity: a meta-analytic review of the behavioral implications of the UPPS for psychopathology. Psychol Assess 2015;27(4):1129-46.

[19] Verdejo-García A, Lozano O, Moya M, Alcázar MA, Pérez-García M. Psychometric properties of a Spanish version of the UPPS-P impulsive behavior scale: reliability, validity and association with trait and cognitive impulsivity. J Pers Assess 2010;92(1):70-7.

[20] Michalczuk R, Bowden-Jones H, Verdejo-Garcia A, Clark L. Impulsivity and cognitive distortions in pathological gamblers attending the UK National Problem Gambling Clinic: a preliminary report. Psychol Med 2011;41 (12):2625-35.

[21] Billieux J, Gay P, Rochat L, Van der Linden M. The role of urgency and its underlying psychological mechanisms in problematic behaviours. Behav Res Ther 2010;48(11):1085-96.

[22] Navas JF, Contreras-Rodríguez O, Verdejo-Román J, Perandrés-Gómez A, Albein-Urios N, Verdejo-García A, et al. Trait and neurobiological underpinnings of negative emotion regulation in gambling disorder. Addiction 2017;112(6):1086-94.

[23] Ledgerwood DM, Alessi SM, Phoenix N, Petry NM. Behavioral assessment of impulsivity in pathological gamblers with and without substance use disorder histories versus healthy controls. Drug Alcohol Depend 2009;105(1-2):89-96.

[24] Alvarez-Moya EM, Jiménez-Murcia S, Aymamí MN, Gómez-Peña M, Granero R, Santamaría J, et al. Subtyping study of a pathological gamblers sample. Can J Psychiatry 2010;55(8):498-506.

[25] Navas JF, Verdejo-García A, López-Gómez M, Maldonado A, Perales JC. Gambling with rose-tinted glasses on: use of emotion-regulation strategies correlates with dysfunctional cognitions in gambling disorder patients. J Behav Addict 2016;5(2):271-81.

[26] Mallorquí-Bagué N, Fagundo AB, Jimenez-Murcia S, de la Torre R, Baños RM, Botella $C$, et al. Decision making impairment: a shared vulnerability in obesity, gambling disorder and substance use disorders? Weinstein AM, editor. PLoS One 2016;11(9)e0163901.

[27] Marazziti D, Picchetti M, Baroni S, Consoli G, Ceresoli D, Massimetti G, et al. Pathological gambling and impulsivity: an Italian study. Riv Psichiatr 2014;49 (2):95-9.

[28] Hodgins DC, Holub A. Components of impulsivity in gambling disorder. Int J Ment Health Addict 2015;13(6):699-711.

[29] Grant JE, Odlaug BL, Chamberlain SR. Gambling disorder, DSM-5 criteria and symptom severity. Compr Psychiatry 2017;75:1-5.

[30] Petry NM, Blanco C, Stinchfield R, Volberg R. An empirical evaluation of proposed changes for gambling diagnosis in the DSM-5. Addiction 2013;108 (3):575-81.

[31] Sleczka P, Braun B, Piontek D, Bühringer G, Kraus L. DSM-5 criteria for gambling disorder: underlying structure and applicability to specific groups of gamblers. J Behav Addict 2015;4(4):226-35.

[32] Choi SW, Shin YC, Kim DJ, Choi JS, Kim S, Kim SH, et al. Treatment modalities for patients with gambling disorder. Ann Gen Psychiatry 2017;16(1):23.

[33] Echeburúa E, Fernández-Montalvo J, Báez C. Predictors of therapeutic failure in slot-machine pathological gamblers following behavioural treatment. Behav Cogn Psychother 2001;29(3):379-83.

[34] Hodgins DC, Currie SR, El-Guebaly N. Motivational enhancement and self-help treatments for problem gambling. J Consult Clin Psychol 2001;69(1):50-7.

[35] Ladouceur R, Sylvain C, Boutin C, Lachance S, Doucet C, Leblond J, et al. Cognitive treatment of pathological gambling. J Nerv Ment Dis 2001;189 (11):774-80.

[36] Jiménez-Murcia S, Álvarez-Moya EM, Granero R, Aymamí MN, Gómez-Peña M, Jaurrieta N. Cognitive-behavioral group treatment for pathological gambling: analysis of effectiveness and predictors of therapy outcome. Psychother Res 2007; 17(5):544-52.

[37] Merkouris SS, Thomas SA, Browning CJ, Dowling NA. Predictors of outcomes of psychological treatments for disordered gambling: a systematic review. Clin Psychol Rev 2016;48:7-31.

[38] Pickering D, Keen B, Entwistle G, Blaszczynski A. Measuring treatment outcomes in gambling disorders: a systematic review. Addiction 2018;113 (3):411-26.

[39] Jiménez-Murcia S, Aymamí-Sanromà M, Gómez-Peña M, Álvarez-Moya E Vallejo J. Protocols de tractament cognitivoconductual pel joc patològic i d'altres addiccions no tòxiques. Spain: Hospital U. Barcelona; 2006.

[40] Jimenez-Murcia S, Aymamí N, Gómez-Peña M, Santamaría JJ, Álvarez-Moya E Fernández-Aranda F, et al. Does exposure and response prevention improve the results of group cognitive-behavioural therapy for male slot machine pathological gamblers? Br J Clin Psychol 2012:51(1):54-71.

[41] Jiménez-Murcia S, Tremblay J, Stinchfield R, Granero R, Fernández-Aranda F, Mestre-Bach G, et al. The involvement of a concerned significant other in gambling disorder treatment outcome. J Gambl Stud 2017;33(3):937-53.

[42] Mestre-Bach G, Granero R, Steward T, Fernández-Aranda F, Baño M, Aymamí N et al. Reward and punishment sensitivity in women with gambling disorder or 
compulsive buying: implications in treatment outcome. J Behav Addict 2016;5 (4):658-65.

[43] Müller KW, Wölfling K, Dickenhorst U, Beutel ME, Medenwaldt J, Koch A. Recovery, relapse, or else? Treatment outcomes in gambling disorder from a multicenter follow-up study. Eur Psychiatry 2017;43:28-34.

[44] American Psychiatric Association. Diagnostic and statistical manual of mental disorders. 4th ed. Washington, DC: American Psychiatric Association; 2018 Text Revision (DSM-IV-TR).

[45] Lesieur HR, Blume SB. The South Oaks Gambling Screen (SOGS): a new instrument for the identification of pathological gamblers. Am J Psychiatry 1987;144(9):1184-8.

[46] Echeburúa E, Báez C, Fernández J, Páez D. Cuestionario de juego patológico de South Oaks (SOGS): validación española. [South Oaks Gambling Screen (SOGS): Spanish validation]. Anális Modif Cond 1994;(20):769-91.

[47] Whiteside SP, Lynam DR, Miller JD, Reynolds SK. Validation of the UPPS impulsive behaviour scale: a four-factor model of impulsivity. Eur J Pers 2005;19(December (7)):559-74.

[48] Aalen O, Borgan O, Gjessing S (Stein). Survival and event history analysis: a process point of view. Springer Science \& Business Media; 2008.

[49] Singer JD, Willett JB. Applied longitudinal data analysis: modeling change and event occurrence. New York: Oxford University Press; 2003.

[50] Billieux J, Lagrange G, Van der Linden M, Lançon C, Adida M, Jeanningros R. Investigation of impulsivity in a sample of treatment-seeking pathological gamblers: a multidimensional perspective. Psychiatry Res 2012;198(2):291-6.

[51] Ramos-Grille I, Gomà-i-Freixanet M, Aragay N, Valero S, Vallès V. Predicting treatment failure in pathological gambling: the role of personality traits. Addict Behav 2015;43:54-9.

[52] Kahler CW, Spillane NS, Metrik J, Leventhal AM, Monti PM. Sensation seeking as a predictor of treatment compliance and smoking cessation treatment outcomes in heavy social drinkers. Pharmacol Biochem Behav 2009;93 (3):285-90.

[53] Foulds J, Newton-Howes G, Guy NH, Boden JM, Mulder RT. Dimensiona personality traits and alcohol treatment outcome: a systematic review and meta-analysis. Addiction 2017;112(8):1345-57.
[54] López-Torrecillas F, Perales JC, Nieto-Ruiz A, Verdejo-García A. Temperament and impulsivity predictors of smoking cessation outcomes. PLoS One 2014;9 (12).

[55] Hershberger AR, Um M, Cyders MA. The relationship between the UPPS-P impulsive personality traits and substance use psychotherapy outcomes: a meta-analysis. Drug Alcohol Depend 2017;178:408-16.

[56] Grant JE, Odlaug BL, Chamberlain SR. Neural and psychological underpinnings of gambling disorder: a review. Prog Neuropsychopharmacol Biol Psychiatry 2016;65:188-93.

[57] Blanco C, Potenza MN, Kim SW, Ibáñez A, Zaninelli R, Saiz-Ruiz J, et al. A pilot study of impulsivity and compulsivity in pathological gambling. Psychiatry Res 2009;167(1-2):161-8.

[58] Bottesi G, Ghisi M, Ouimet AJ, Tira MD, Sanavio E. Compulsivity and impulsivity in pathological gambling: does a dimensional-transdiagnostic approach add clinical utility to DSM-5 classification? J Gambl Stud 2015;31 (3):825-47.

[59] Chamberlain SR, Stochl J, Redden SA, Odlaug BL, Grant JE. Latent class analysis of gambling subtypes and impulsive/compulsive associations: time to rethink diagnostic boundaries for gambling disorder? Addict Behav 2017;72:79-85.

[60] Goudriaan AE, Oosterlaan J, De Beurs E, Van Den Brink W. The role of selfreported impulsivity and reward sensitivity versus neurocognitive measures of disinhibition and decision-making in the prediction of relapse in pathological gamblers. Psychol Med (Paris) 2008;38(1):41-50.

[61] Goudriaan AE, Oosterlaan J, De Beurs E, Van Den Brink W. Neurocognitive functions in pathological gambling: a comparison with alcohol dependence, Tourette syndrome and normal controls. Addiction 2006;101(4):534-47.

[62] Leblond J, Ladouceur R, Blaszczynski A. Which pathological gamblers will complete treatment? Br J Clin Psychol 2003;42(2):205-9.

[63] Slutske WS, Caspi A, Moffitt TE, Poulton R. Personality and problem gambling: a prospective study of a birth cohort of young adults. Arch Gen Psychiatry 2005;62(7):769-75.

[64] Bücker L, Bierbrodt J, Hand I, Wittekind C, Moritz S. Effects of a depressionfocused internet intervention in slot machine gamblers: a randomized controlled trial. PLoS One 2018;13(6). 